\title{
The Role of Basic Need Satisfaction in English Learning: A Case Study at a University in China
}

\author{
Pingying Hu \\ School of Humanities, Fujian University of Technology, China
}

Copyright $(2016$ by authors, all rights reserved. Authors agree that this article remains permanently open access under the terms of the Creative Commons Attribution License 4.0 International License

\begin{abstract}
To examine the role of learners' innate need satisfaction in their English foreign language (EFL) learning, a case study was conducted at a university in China. Both qualitative and quantitative methods were employed in the study. Data were collected via a pre- and post-assessment research design and by recording dynamic variability in student participants' $(\mathrm{N}=353)$ learning performance while implementing a need-satisfying intervention scheme for one academic year. Structural equation modelling (SEM) method was used to test the hypothesized model and the structural relationship. Outcomes of this study indicated 1) that satisfaction of learners' basic needs for competence, autonomy and relatedness strengthened their autonomous motivation and facilitated controlled motivation to move gradually to autonomous one; 2) that strengthened motivation contributed to positive learning performance and significant improvement in their English proficiency; 3) and interestingly, that the causal effect coefficients of the contribution paths changed erratically with the variation of learners' motivation and English proficiency level. The present study suggested that innate need satisfaction was basically related to EFL learning outcome, but that fulfillment of different psychological needs played varied roles in academic achievement. The interesting findings signified that cultural factors and instrumental motivation had a notable impact on causal effects of innate need satisfaction on EFL learning outcome.
\end{abstract}

Keywords Need Satisfaction, Self-determined Motivation, EFL, Learning Outcome

\section{Introduction}

English foreign language (EFL) teachers in China are often confronted with students' amotivation and controlled regulation in EFL course education. To achieve optimal EFL learning and teaching outcomes, EFL learners need to be motivated and trained to learn autonomously and effectively. As Harmer (2001: 335) [1] put it, however good a teacher may be, students will never learn a language unless they aim to learn outside as well as inside classroom. However, in the school-based EFL learning context, rarely are the learners intrinsically motivated. More often, their learning motivation is externally regulated. Many students learn EFL for external rewards, or to avoid negative academic consequences. As EFL practitioner, we find it a tough job to stimulate learners' self-determined motivation. Pintrich (2003)[2] argued that to further our understanding of students' motivation, we need to identify learners' basic needs that define what individuals want. Based on an integrated approach to studying the simultaneous relationship of basic human needs and social-cognitive influences, SDT is structured uniquely to allow empirical examinations of the relationship between innate human needs and motivation. Additionally, researches on SDT in education have revealed that autonomous motivation (intrinsic motivation and identified regulation) led to more effective learning and better academic achievement than controlled motivation (external regulation and introjected regulation) did (Deci, Ryan \& Williams, 1996; Zeng \& Luo, 2012; Taylor, et al., 2014)[3, 4, 5]. The purpose of this study aims to examine whether satisfaction of learners' basic psychological needs in EFL course education contributes to their learning outcome, on which little research has been conducted.

\subsection{Theoretical Background}

The self-determination theory (SDT; Deci \& Ryan, 1985; Ryan \& Deci, 2000)[6, 7] is a macro theory of human motivation and personality, which concerns people's inherent growth tendencies and basic psychological needs for autonomy, competence and relatedness. SDT argues that satisfaction of basic psychological needs for competence, autonomy and relatedness fosters the most volitional and high quality forms of motivation and engagement for activities, including enhanced performance, persistence, and creativity, while frustration of the basic needs leads to diminished motivation and well-being. Overall, research on SDT indicates that contexts supportive of the basic needs 
were found to foster greater internalization and integration than contexts that thwart satisfaction of these needs (Ryan \& Deci, 2000; Ushioda, 2006)[7, 8]. Therefore, SDT defines these needs as essential psychological nutriments for people's ongoing psychological growth, integrity and well-being (Ryan, Sheldon, Kasser \& Deci, 1996; Deci \& Ryan, 2000:229)[9, 10]. In brief, competence refers to feeling effective in one's actions (Deci \& Ryan, 1985)[6], and the experience of a sense of effectiveness in interacting with the environment, optimally challenging tasks and attaining desired outcomes (White, 1959; Skinner, 1995)[11, 12]. A sense of competence is enhanced by engaging optimal challenges and receiving positive performance feedback; whereas it is diminished by too difficult or too easy tasks and negative feedback (Deci, 1975)[13]. The more competent a person perceives in an activity, the more intrinsically motivated he will be for that activity (Deci \& Ryan, 1985)[6]. Autonomy is defined as the experience of volition and the self-endorsement of one's activity (Ryan \& Connell, 1989)[14], but by no means as individuals' inner control, detachment, helpless or individualism (Deci, Koestner \& Ryan, 1999)[15]. When experiencing autonomy, an individual regulates his own behavior by governing the initiation and direction of an action (Ryan \& Powlson, 1991)[16]. Relatedness can be understood as the desire to interact and to feel connected with significant others and having a sense of belonging within one's community (Deci \& Ryan, 1991; Ryan \& Deci, 2000)[17, 7]. That is, the experience of a sense of mutual respect, love and care with significant others (Baumeister \& Leary, 1995)[18] facilitates individuals' behavioral and emotional engagement in the activities that are congruent with their developing identities (Ryan, 1995)[19].

It is noteworthy that the innate psychological needs are objective rather than subjective (Braybrooke, 1987)[20]; people require them whether or not they think they do, and failures of satisfaction will have specifiable negative consequences. In EFL education, learners' need for competence is satisfied when they get necessary meta-cognitive and cognitive strategy training, which makes them feel confident enough to carry out or to challenge a learning task. Their need for autonomy is met when they are allowed to make their own choices and decisions but not compelled to complete different kinds of learning tasks by some external force. Their need for relatedness is fulfilled when they develop close relationships with important others (peers and teachers) and feel that these individuals are invested in and care about them. In other words, by allowing students to learn in their own way (autonomy), providing them with the tools to succeed (competence), and removing authoritarian barriers (relatedness), instructors can give their students an interesting, challenging, and intrinsically motivating educational experience (Filak \& Sheldon, 2003)[21].

\subsection{Research Questions}

Based on the theoretical background and the aim of the study, two research questions were formulated as follows.

RQ1: How to motivate learners to learn EFL autonomously and effectively?

RQ2: Is satisfaction of learners' innate needs positively related to their EFL learning outcome?

According to the research questions, it was hypothesized

1) that creating learning climates and contexts that allow satisfaction of learners' basic psychological needs for autonomy, competence and relatedness would motivate them to learn EFL autonomously and effectively; and

2) that satisfying learners' basic psychological needs would generate self-regulated and effective learning behaviors which would lead to optimal EFL learning performance and academic achievement.

Accordingly, the hypothesized SDT model describing the relationship between need satisfaction and EFL learning outcome was depicted as Figure 1.

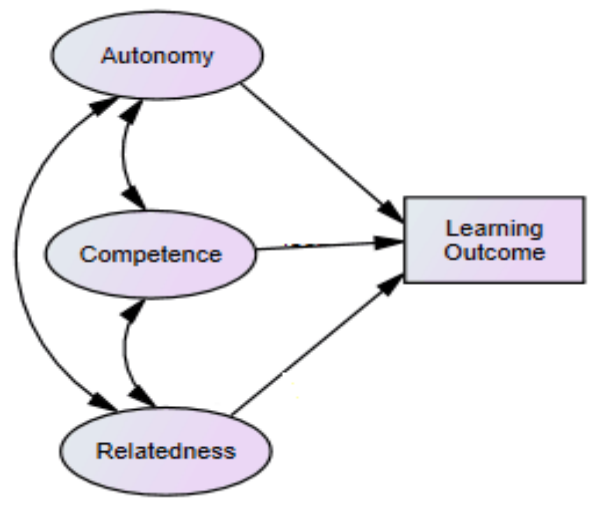

Figure 1 . Hypothesized SDT model

The theorized model above displays the correlation between three innate needs and their contribution to EFL learning outcome. Apparently, the basic psychological needs form three contribution paths to EFL learning outcome and play an important role respectively in the causal effect.

\section{Method}

This study involved an action program, following five-step iterations, each of which was adapted in response to the students' interactions. Firstly, identifying the students' needs in EFL learning through the pre-survey and pre-test; secondly, planning a need-satisfying intervention scheme, that is, incorporating learners' basic need satisfaction into the EFL course education; thirdly, implementing the intervention scheme in Group A for one academic year, while Group B just following the normal EFL course; fourthly, evaluating the need-satisfying scheme by comparing and contrasting the results of the pre- and post-assessments between two groups, and by analyzing the qualitative data gathered from interviews and observation journals; lastly, reflecting on the strengths and weaknesses of the intervention scheme and revising it. 


\subsection{Participants}

The participants in the study included 353 college students of 8 teaching classes randomly chosen from an engineering college and $10 \mathrm{EFL}$ teachers from the same research group. The students were divided into two homogeneous groups: Group A with 180 students of 4 classes, and Group B with 173 students of another 4 classes. Four EFL teachers were assigned to teach two classes, one from Group A and the other from Group B. The other six peer teachers took turns to observe the in-class teaching and learning, measured and recorded the students' learning performance.

\subsection{Measures}

In order to answer the research questions, the instruments such as the questionnaire, interviews, tests and observation journals were employed to collect data. Based on the data collected, the following variables were measured: (1) perceived satisfaction of three psychological needs, (2) two types of learning motivation, (3) EFL learning performance, and (4) English proficiency.

The questionnaire consisted of two parts: basic need satisfaction and learning motivation, including five subscales with 30 items. The formerly validated instrument "the Basic Psychological Need Satisfaction and Frustration Scale" (Chen, Vansteenkiste, et al., 2015)[22] was adapted to measure the students' perceived satisfaction of innate needs for autonomy, competence and relatedness. The adapted version included three subscales, each of which consists of 6 questions. The previously validated questionnaire "Learning --- Self-Regulation Questionnaire" (Williams \& Deci, 1996; Black \& Deci, 2000)[23, 24] was adapted to investigate the students' EFL learning motivation. This part was formed with just two subscales: autonomous regulation (intrinsic motivation or identified regulation) and controlled regulation (introjected or external regulation) with 12 items. The student participants were required to respond to a 7-point Likert scale ranging from 1 (not at all true) to 7 (very true) to indicate the degree to which the statement was true for them. The questionnaire was piloted and revised to avoid misunderstanding, and was used for both the pre- and post-survey. In various validations involving factor-analytical procedures for construct validity, the modified questionnaire has shown distinct factor structures and good internal reliability $(\alpha>.80)$; except controlled regulation showing a relatively weak but still acceptable reliability $(\alpha \approx .67)$.

Interviews were conducted to better understand the students' perceived need satisfaction, learning motivation and possible causes. Three open-ended questions related to the questionnaire and learning behavior were set for follow-up interviews as a supplement of the surveys.

English proficiency tests were conducted before and after the implementation of the need-satisfying intervention scheme. Since both the reliability and validity of the International English Language Testing System (IELTS) are good, two IELTS academic papers of the same level were chosen to test the students' English proficiency. The original papers consisted of four parts: listening, reading, writing and speaking, but the pre-test and post-test went without speaking due to the difficulty in ensuring objective assessment of speaking test. Additionally, the score of the paper was adapted to 90 points with 30 for each of the three parts (listening, reading and writing) for convenient and accurate marking.

Observation journals were kept by the 6 peer teachers when observing the in-class teaching and learning. Data collected from the observation journals recorded the students' learning performance, providing evidences for assessment of the students' learning outcome.

\subsection{Data Collection}

The researchers and participating teachers collected data in regular English classes. It was convenient to administrate and instruct surveys and tests. The students' perceived need satisfaction, learning motivation and English proficiency were measured among all student participants in both preand post-assessments so that growth and improvements could be calculated and then compared between Group A and B. Moreover, qualitative data were collected from interviews and observation journals. Regular English classes were also real and natural scenes for peer teachers to observe and assess students' learning performance. The students' learning performance and its variability of both groups were observed, measured and kept in observation journals.

\subsection{Data Analyses}

Student participants' response to the pre- and post-survey and the score of pre- and post-test were used for data analysis. SPSS 22.0 was used to do both descriptive statistics analysis and confirmatory factor analysis. IBM SPSS Amos 22.0 was employed to test the hypothesized model (see Figure 1) with structural equation modelling (SEM) method. The data collected from interviews were coded in simple form (Table 2 ), focusing on outstanding and common views. The observation journals were coded by mainly quoting some typical, common and convincing comments on Group A. The quantitative statistics and the qualitative data supported each other to answer the research questions.

\section{Results}

This study yielded a rich set of data that provided valuable insights into the perception and practices of EFL education. Two sets of data were collected to measure the variability in the students' perceived need satisfaction and EFL learning motivation. Additionally, the participants' learning achievement or progress in English proficiency was examined by comparing results of the pre-test and post-test. Lastly, the hypothesized relationship between need satisfaction and learning outcomes was tested with SEM. Moreover, the students' learning performance was observed and recorded. The qualitative data supported the results of quantitative analysis. 


\subsection{Descriptive Statistics Analysis}

\subsubsection{Results of the Questionnaire}

Results of the questionnaire collected from both the pre-survey and post-survey were listed and compared as follows (Table 1), which indicated that satisfaction of learners' psychological needs for autonomy, competence and relatedness predicted positively to their learning motivation.

Table 1 shows mean of Group A and Group B, standard deviations (SD) and Cronbach's alphas $(\alpha)$ for each subscale of the surveys, displaying change in the student participants' perceived need satisfaction and learning motivation before and after the implementation of the need-satisfying scheme in Group A. Obviously, the pre-survey's mean of both groups was slightly over medium and quite similar, but there was quite a large gap between the mean of the two groups in the post-survey, which suggested that Group A's psychological needs were much better satisfied. As a result, their autonomous motivation strengthened while controlled motivation decreased much more significantly than those of Group B. It could also be observed that Group B's mean between the pre-survey and post survey had no significant change. The results answered the first research question and confirmed the first hypothesis that satisfying learners' basic needs contributed to enhancement of their academic motivation.

\subsubsection{Data Gathered from Interviews}

Common and typical views from interviews were summarized and compared as follows (Table 2). Data coded in the table were mainly about Group A because the need-satisfying intervention scheme had been implemented only in Group A. Another reason was that Group B got similar answers to those of Group A's pre-interviews in preand post interviews.

Table 1. Results of the Questionnaire

\begin{tabular}{cccccccccc}
\hline \multirow{2}{*}{ Subscales } & \multicolumn{4}{c}{ Mean of Pre-survey } & \multicolumn{5}{c}{ Mean of Post-survey } \\
\cline { 2 - 9 } & GrA & GrB & SD & $\alpha$ & GrA & GrB & SD & $\alpha$ \\
\hline Need for autonomy & 4.31 & 4.28 & 1.53 & .77 & 5.48 & 4.58 & 1.27 & .75 \\
Need for competence & 4.27 & 4.30 & 1.62 & .86 & 5.63 & 5.01 & 1.34 & .87 \\
Need for relatedness & 4.89 & 4.91 & 1.56 & .83 & 6.05 & 4.77 & 1.65 & .85 \\
Autonomous motivation & 3.87 & 3.85 & 1.61 & .79 & 5.06 & 3.90 & 1.48 & .81 \\
Controlled motivation & 4.64 & 4.66 & 1.69 & .67 & 3.42 & 4.71 & 1.82 & .78 \\
\hline
\end{tabular}

Note: GrA: Group A; GrB: Group B; SD and $\alpha$ of the pre-survey or post- survey were of all participants including Group A and B.

Table 2. Data Gathered from Interviews

\begin{tabular}{|c|c|c|}
\hline Questions & Answers from pre-interviews & Answers from post interviews \\
\hline $\begin{array}{l}\text { Q1: Are your } 3 \\
\text { innate needs } \\
\text { satisfied in EFL } \\
\text { education? } \\
\text { Explain in } \\
\text { details. }\end{array}$ & $\begin{array}{l}\text { Not fully satisfied. } \\
\text {--to follow teachers' arrangements, feel compelled and } \\
\text { bored to complete learning tasks; but if offered to make our } \\
\text { own decisions, we had no idea what to do, we might choose } \\
\text { to play games instead. } \\
\text {--learning strategies are needed to learn more effectively;; } \\
\text {--to try to work on my own, not to bother others, but } \\
\text { encouragement from teachers and peers push me forward. }\end{array}$ & $\begin{array}{l}\text { Better satisfied. } \\
\text {--to make our own choices except following the teacher or the } \\
\text { course books, but not sure if it helps to pass exams; } \\
\text {--to learn better and more effectively with learning strategies; but } \\
\text { EFL is not a must in our daily life, we will learn or do something } \\
\text { else after passing the exams; } \\
\text {--to enjoy working with peers and presenting what we learned } \\
\text { together, but it's time-consuming. }\end{array}$ \\
\hline $\begin{array}{l}\text { Q2: How do you } \\
\text { think about your } \\
\text { learning } \\
\text { motivation? }\end{array}$ & $\begin{array}{l}\text {--to learn English so as to pass exams, to get a better job, to } \\
\text { study or travel abroad, to learn about world affairs, to watch } \\
\text { international sports games, to play games; } \\
\text {--to find it useless learning EFL. If I can choose, I will do } \\
\text { anything else. }\end{array}$ & $\begin{array}{l}\text {--to learn English so as to pass exams, to get a better job, to study } \\
\text { or travel abroad, to learn about world affairs, to watch } \\
\text { international sports games, to play games; } \\
\text {--to challenge English for future career development and to } \\
\text { communicate with foreigners. }\end{array}$ \\
\hline $\begin{array}{l}\text { Q3: What do } \\
\text { you usually do } \\
\text { to improve your } \\
\text { English? }\end{array}$ & $\begin{array}{l}\text {--to rely on teachers' plans, assignments and assessment to } \\
\text { gain some knowledge and cognitive strategies; } \\
\text {--to lack strong will to keep learning going after class; } \\
\text {--to feel frustrated at little and slow progress, then give up. }\end{array}$ & $\begin{array}{l}\text {--to set self-determined learning plan and try hard to follow; } \\
\text {-- to regulate learning according to my own needs; } \\
\text {-- to find a couple of classmates to do collaborative learning so } \\
\text { that we encourage and push each other forward.. }\end{array}$ \\
\hline
\end{tabular}


Data collected from interviews were in line with the results of the questionnaire. Most students from Group A confirmed that their basic needs were better satisfied in the implementation of the intervention scheme, which facilitated them to regulate their learning actively. They also upheld that acquisition of necessary skills and strategies empowered them to learn EFL effectively, and that they appreciated teachers' support and encouragement, and enjoyed collaborative learning which made tedious learning interesting and maintained their learning enthusiasm. Nevertheless, some students mentioned that there were not many opportunities for them to use English in EFL contexts, so they might not keep working on EFL when they gained competence in English. On the other hand, Group B gained knowledge of EFL and mastered some cognitive strategies for English learning, but they admitted that they lacked strong will to persist in EFL learning beyond class. Noteworthily, quite a few students confessed that being given autonomy without any constraint might not work well with them owing to their weak willpower and self-control. Apart from the two interesting viewpoints mentioned above, the results basically validated the first hypothesis that creating learning climates and contexts that allow satisfaction of learners' basic psychological needs would motivate them to learn autonomously and effectively.

\subsubsection{Results of Proficiency Tests}

The result of the pre-test was used to do an independent-samples $\mathrm{T}$ test, with mean of Group A and Group B 53. 8750 and 53.0606 respectively, $\mathrm{F}=.278$, $\mathrm{t}=.521, \mathrm{p}=.604>.05$. This justified that the difference between Groups A and B was not significant, indicating that the two groups were homogeneous with similar English proficiency.

The results of pre-test and post-test of the two groups were listed and compared below (Table 3 ).

Table 3. Comparison of Pre-test and Post-test

\begin{tabular}{ccccc}
\hline & \multicolumn{2}{c}{ Group A } & $(\mathrm{N}=180)$ & \multicolumn{2}{c}{ Group B $(N=173)$} \\
\cline { 2 - 5 } & mean & $\mathrm{SD}$ & mean & $\mathrm{SD}$ \\
\hline Pre-test & 53.8750 & 6.35145 & 53.0606 & 6.33906 \\
Post-test & 65.1250 & 5.21235 & 58.7576 & 8.00402 \\
\hline
\end{tabular}

Comparing the mean of pre-test and post-test, we were convinced that Group A had made greater progress than Group B after one academic year's study. It was also worth noting that SD of the two groups moved in opposite ways (see Table 2), indicating that individual difference in English proficiency reduced in Group A but increased significantly in Group B.

Fittingly, the independent-samples $\mathrm{T}$ test of the post-test of two groups also proved that the difference between two groups' progress was significant, $\mathrm{F}=1.324, \mathrm{t}=3.306$, $\mathrm{p}=.002<.05$. Moreover, the author conducted ANOVA analysis of both groups' pre-test and post-test respectively. Results of ANOVA analysis suggested that the progress of
Group A was significant, F $(1,62)=44.037, \mathrm{p}=.000<.05$; and that Group B also made significant progress, $\mathrm{F}(1,64)=$ $10.274, p=.004<.05$, but not as much as that of Group A. The results supported the second hypothesis that self-determined behaviour in EFL learning would lead to good academic achievement and improved EFL proficiency.

\subsubsection{Evidences from the Journals}

Data collected from the observation journals described the in-class learning climate, the students' learning attitude, learning performance and so on. In the first couple of months, there wasn't much difference between the two groups. Then gradually Group A became more and more active and enthusiastic in presenting collaborative learning outcomes, providing comments and assessment for classmates, whilst Group B were somewhat passive. Some typical comments on Group A were quoted as follows.

"Quite a few students somewhat feel bored in strategy training, but they tend to use some strategies to do exercises effectively."

---- Julia

"It seems that the students are now more proactive in learning what they are interested in. Obviously, the students bring their potential into full play to learn EFL when they are allowed to make their own decision and to choose what they like."

---- Chris

"It is amazing to watch students' well-prepared and creatively-presented group work. The innovative elements and their special way of presenting often arouse laughter, and attract fellow students' attention. It seems that collaborative learning motivates students to challenge difficult learning tasks together and to do better jobs."

---- Amy

"Recently, Group A give me a big surprise from time to time. They perform very well in cosplay, English movie dubbing, English story-telling, international sports news broadcasting, English learning skill and strategy introduction and so on. Most of the classmates and the teachers are fascinated and interact enthusiastically."

---- Aileen

Moreover, the observation journals revealed that the supportive and interactive climate encouraged the students to learn enthusiastically. The comments and feedback from the teachers and peers functioned as a "stimulant" for many students to reflect on their work and regulate their learning positively. These evidences verified the positive effect of the need-satisfying intervention scheme and confirmed the second research hypothesis that satisfying learners' basic psychological needs would generate self-regulated and effective learning behaviors which would lead to optimal EFL learning performance and academic achievement. 


\subsection{Confirmatory Factor Analysis}

In order to get persuasive research outcomes, the structural equation modelling (SEM) method was used to examine the factor structure of SDT and to test the hypothesized relationship between participants' perceived satisfaction of psychological needs and the learning outcome. Since the need-satisfying scheme was implemented only in Group A, data collected from Group A was used for the analysis of this part. Besides, as learning performance could not be objectively evaluated, results of the proficiency tests were used to represent the learning outcome in the SEM. The confirmatory factor analysis includes measurement model analysis and structural model analysis.

\subsubsection{Measurement Model Analysis}

The measurement model covered one manifest variable (academic achievement) and three latent variables: satisfaction of needs for autonomy, competence and relatedness. The reliability test of the questionnaire showed its overall Cronbach's alpha reaching .825 , suggesting that these measures were internally consistent. The relationship between measures and their latent factors was determined by using the maximum likelihood method with all factors allowed to co-vary so that possible discrepant associations could be identified. The observed variables and their factor loading were listed in Table 4.

Table 4. Factor Loadings in the Measurement Model

\begin{tabular}{ccccccc}
\hline Factors & $\mathrm{V} 1$ & $\mathrm{~V} 2$ & $\mathrm{~V} 3$ & $\mathrm{~V} 4$ & $\mathrm{~V} 5$ & $\mathrm{~V} 6$ \\
\hline autonomy & & .607 & .680 & .704 & .505 & \\
competence & .728 & .706 & .750 & .596 & .709 & .637 \\
relatedness & .589 & & .675 & .512 & .598 & \\
\hline
\end{tabular}

Note: $\mathrm{p}<.0 .1 ; \mathrm{V}$ : observed variable; Variables with factor loading $\leq 0.5$ were left out.

Table 4 shows that the measured variables were significantly loaded on their corresponding factors, ranging from .505 to .750 , which suggested that confirmatory factor analysis could be conducted based on the data set.

The model-data goodness-of-fit tests were conducted using IBM SPSS Amos 22.0, and evaluated according to the fit indices and their acceptable thresholds provided by Hooper, Coughlan and Mullen (2008)[25]. As shown in table 5 , the listed absolute fit indices: $\mathrm{X}^{2}(1036 / 441)$ was 2.35
( $>$ > .05), RMSEA was .061 (<.07); the incremental fit indices: NFI, TLI and CFI were around .95; and the parsimony fit indices: PNFI and PCFI were over .50, indicating that the factor structure based on SDT fit well with the collected data. The indices of goodness-of-fit tests also justified the validity of the questionnaire and the reliability of the measurement model. Therefore, further structural modelling analysis could be conducted on the data.

\subsubsection{Structural Model Analysis}

The purpose of the structural model analysis was to examine the hypothesized model in SEM. The hypothesized relationship between learners' psychological needs and their learning outcome was examined before and after the need-satisfying intervention scheme separately. This revealed a varied effect of the contribution paths of need satisfaction to EFL learning outcome at different stages of learning (Figure $2 \& 3$ ).

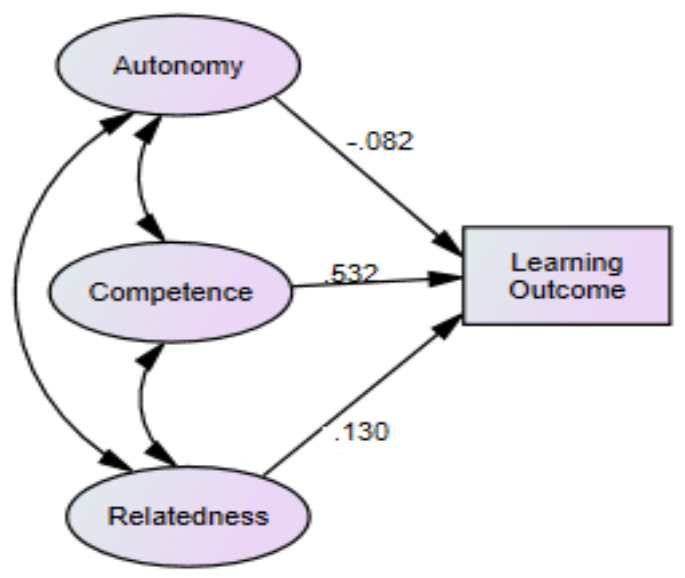

Figure 2. Hypothesized model pre-examined in SEM

Figure 2 shows that the pre-examined model confirmed two causal paths: competence $\rightarrow$ learning outcome, relatedness $\rightarrow$ learning outcome. The finding suggested that a controlled EFL learner's perceived satisfaction of competence and relatedness predicted positively to his learning outcome. However, satisfaction of his need for autonomy had slightly negative prediction to the learning outcome.

Table 5. Indices of Goodness-of-fit Tests

\begin{tabular}{cccccccc}
\hline Indices & $\mathrm{X}^{2}$ & RMSEA & NFI & TLI & CFI & PNFI & PCFI \\
\hline Result & 2.35 & .061 & .925 & .947 & .952 & .564 & .615 \\
\hline
\end{tabular}




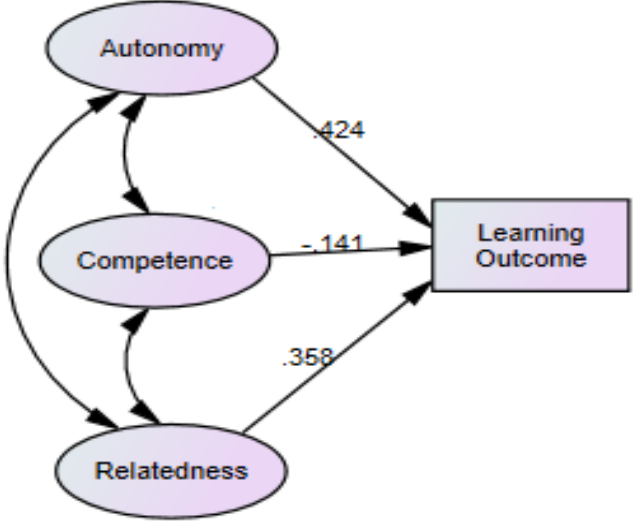

Figure3. Hypothesized model post-examined in SEM

The post-examined model (Figure 3) also confirmed two causal paths: autonomy $\rightarrow$ learning outcome, relatedness $\rightarrow$ learning outcome. This finding indicated that perceived satisfaction of autonomy and relatedness could empower a relatively autonomous learner to gain higher academic persistence and better academic achievement, Whereas, satisfaction of his need for competence predicted somewhat negatively to his learning outcome.

Results of the structural model analysis were roughly in line with the hypothesized SDT model (See Figure 1). The causal effects of the contribution paths between need satisfaction and the learning outcome both before and after the intervention were listed in as follows (Table 6).

Table 6. Standardized direct effects of the theorized causal paths in SEM

\begin{tabular}{ccccc}
\hline \multirow{2}{*}{ Causal Paths } & \multicolumn{2}{c}{$\begin{array}{c}\text { Before } \\
\text { Intervention }\end{array}$} & \multicolumn{2}{c}{ After Intervention } \\
\cline { 2 - 5 } & $\mathrm{P}$ & Estimate & $\mathrm{P}$ & Estimate \\
\hline $\begin{array}{c}\text { Autonomy } \rightarrow \text { Learning } \\
\text { Outcome }\end{array}$ & .006 & -.082 & .000 & .424 \\
$\begin{array}{c}\text { Competence } \rightarrow \text { Learning } \\
\text { Outcome }\end{array}$ & .000 & .532 & .003 & -.141 \\
$\begin{array}{c}\text { Relatedness } \rightarrow \text { Learning } \\
\text { Outcome }\end{array}$ & .004 & .130 & .000 & .358 \\
\hline
\end{tabular}

Note: $\mathrm{p}<.05$

Table 6 reports standardized direct causal effects of the contribution paths and their $\mathrm{P}$ value before and after the intervention. The pre-examined results suggested that learners' perceived competence contributed $53 \%$ to their learning outcome, and relatedness $13 \%$, while autonomy had an $8 \%$ negative effect on the learning outcome. The possible explanation for the findings was that most student participants had controlled motivation before the intervention (see Table 1). The results was supported by the data gathered from the pre-interviews (as shown in Table 2) that controlled learners hungered for EFL learning strategies, and had a need for certain degree of support and encouragement from peers and teachers. They confessed that given full autonomy without any constraint might not work well with them owing to their weak willpower and self-control.

Whereas, results examined after the intervention (see
Table 6) revealed different contribution of the three causal paths, the subjects' perceived autonomy contributed $42 \%$ to their learning outcome, relatedness $36 \%$, but competence had a $14 \%$ negative effect on their learning outcome. The interviewees' responses in post-interviews (Table 2) affirmed that both autonomy and relatedness were necessary for autonomous learners to gain optimal learning outcome, but that lack of authentic contexts and limited opportunities for using EFL lowered their persistence and enthusiasm when their English was competent.

\section{Discussion}

\subsection{Overall Function of Need Satisfaction}

In this case study, both descriptive statistics analysis and confirmatory factor analysis indicated that satisfaction of learners' basic psychological needs for competence, autonomy and relatedness predicted positively to their EFL learning outcome. Specifically, basic need satisfaction strengthened learners' autonomous motivation and facilitated controlled motivation to move gradually to autonomous one. Consequently, strengthened motivation and self-regulated learning behavior contributed to optimal learning performance and academic achievement.(EFL proficiency). Interestingly, different psychological needs when satisfied played varied role in achieving EFL learning outcome. Outcomes of the present study signified that relatedness was required in EFL learning contexts without regard to learners' existing English level and learning motivation. Competence was essential to motivate controlled learners to improve their EFL proficiency. Whereas, autonomy was particularly important for autonomous learners. Generally, results of this study were compatible with the findings of relevant researches (Deci \& Ryan, 1985; 2000; Deci, Ryan \& Williams, 1996; Ryan \& Deci, 2006; etc.) $[6,10,3,26]$ that satisfying learners' psychological needs for autonomy, competence and relatedness contributed to self-determined motivation. Black and Deci's (2000)[24] study showed that students' perceptions of autonomy support from their instructors predicted increases in self-regulation, perceived confidence in the subject, and a decrease in anxiety regarding a course grade. Some researchers (Ushioda, 2006 and Hua, 2009)[8,27] proposed that self-determined motivation was closely related to learner autonomy. Little (2000)[28], Wang (2002)[29], Mozzon-McPherson and Dantec (2006)[30] stressed the importance of strategy training in developing learner autonomy and improving academic achievement. Green-Demers and Pelletier (2003)[31] found that when peers and teachers fostered relatedness through providing affiliation and interpersonal support, students were more engaged in and committed to academic endeavors, which in turn enhanced their overall well-being. Conversely, Legault 
et al.(2006)[32] demonstrated that a lack of interpersonal support was significantly associated with motivational issues such as having difficulty in internalizing the importance of academic activities, having trouble in developing and sustaining motivation at school.

\subsection{Contribution Paths to Learning Outcome}

Results of confirmatory factor analysis generally justified the hypothesized relationship between satisfaction of learners' basic needs and their learning outcome in EFL education. This finding agreed with the results of the research by Badri, et al. (2014)[33] that fulfillment of basic needs and intrinsic motivation has positive effect on academic achievement. Specifically, results of confirmatory factor analysis revealed that when their academic motivation was somewhat controlled, learners had a strong desire for competence and a need for relatedness, but no need for autonomy. When their learning motivation moved towards relatively autonomous one, they required both autonomy and relatedness, but not competence. Obviously, the effects of the contribution paths changed erratically with the growth of learners' motivation and the improvement of English proficiency. These findings implied linkage between cultural factors, instrumental motivation and EFL learning outcome.

Cultural factors had an impact on the effect of the contribution paths. The outcomes of the present study indicated that relatedness was frequently required by Chinese EFL learners. China's collectivistic culture made most the students prefer collaborative learning to independent learning. Supportive learning contexts would motivate them to learn enthusiastically. Autonomy had slight negative contribution effect on EFL learning outcome for controlled learners, because traditional educational culture in China generated reactive or "obedient" learners who were used to following teachers' arrangements, but not good at making their own decisions. As for autonomous learners, autonomy had quite strong positive contribution to their learning outcome. No autonomy made them feel bored at EFL learning.

Additionally, results of this study suggested that instrumental motivation also affected the effect of the contribution paths. The instrumentally motivated learners desired for competence and relatedness, because competence enabled and motivated them to learn effectively. However, once they gained competence in EFL, they might not feel an urgency to learn owing to limited opportunity to use it in EFL contexts, and thus their motive weakened gradually. At the same time, they needed encouragement and support from teachers and peers. Autonomy was a double-edged sword for them. On one hand, they longed for self-decision and free choices. On the other hand, they might not use autonomy properly. As Buss (2013)[34] put it, possession of authority over their actions was no guarantee that they had the power to determine how to exercise the authority properly. In other words, the instrumentally motivated students hungered for the freedom of making their own choices, but they needed assignments and learning tasks to push them forwards.

\section{Conclusion and Implication}

\subsection{Conclusion and Implication}

The study examined the role of learners' innate need satisfaction in their EFL learning outcome. Overall, outcomes of the study validated that satisfying learners' psychological needs for autonomy, competence and relatedness facilitated the internalization progress of extrinsic motivation, which motivated them to learn autonomously and effectively, and that self-determined motivation and positive self-regulated learning led to a good learning outcome. Interestingly, the study also suggested that each of the three psychological needs had varied impact on EFL learning outcome, and that the effects of the contribution paths (path coefficients) changed erratically with the growth of learners' academic motivation and English proficiency level.

This study also revealed that cultural factors and instrumental motivation had noticeable influence on the applied study on SDT in education. SDT was primarily based on western culture which tends to support independent individuals, while Chinese culture broadly advocates collectivism. China's collectivistic culture explains why relatedness had positive effect on the learning outcome at different stages, which also proved that interactive and collaborative learning could effectively stimulate learning motivation (Lantolf, 2000)[35]. Additionally, the educational system and EFL learning context in China resulted in instrumental motivation, which could account for the interesting phenomenon that satisfaction of autonomous EFL learners' need for competence had some negative effect on their learning outcome in China. Due to the "obedient" educational culture in China and learners' controlled motivation, full autonomy had slight negative prediction to the controlled learners' learning outcome.

\subsection{Limitation and Suggestion}

Obviously, this study had some limitations. First of all, further studies should be conducted to clarify the two unexpected findings of the study, especially the finding that the more competent the EFL learners perceived, the apparently less positive effect it had on their learning outcome. Moreover, since the sample in this case study was college students in China, generalization of the findings to the students of other cities and countries was limited. To increase the generalizability of the results of this study, repetition of research with other groups of school and university students is recommended. In addition, one academic year's intervention was not enough to precisely 
test the causal effects of the three contribution paths between need satisfaction and the learning outcome. Given more time, the action program would be carried out a few more rounds to get more evidences or more convincing results. Furthermore, a comparative study between psychological need satisfaction and other motivation-oriented factors could be conducted to contrast the causal effect on EFL learning outcome. As a result, both EFL practitioners and learners would benefit from the comprehensive research outcomes.

\section{REFERENCES}

[1] J. Harmer. The Practice of English Language Teaching (3rd edn.). London: Pearson Education, 2001.

[2] P. R. Pintrich. A motivational science perspective on the role of student motivation in learning and teaching contexts. Journal of Educational Psychology, 95, 667-686, 2003.

[3] E. L. Deci, R. M. Ryan \& G. C. Williams. Need satisfaction and the self-regulation of learning. Learning and Individual Differences, 8, No.3, 165-183, 1996.

[4] X. H. Zeng \& J. W. Luo. A study on the relationship between engineering college students' English learning motivation and English achievements. Journal of Guangdong University of Technology (Social Sciences Edition), 12, No.1, 72-76, 2012. (In Chinese)

[5] G. Taylor, T. Jungert, G.A. Mageau, K. Schattke, H. Dedic. A self-determination theory approach to predicting school achievement over time: the unique role of intrinsic motivation. Contemporary Educational Psychology, 39, No.4, 342-358, 2014.

[6] E. L. Deci \& R. M. Ryan. Intrinsic Motivation and Self-determination in Human Behavior. New York: Plenum Press, 1985.

[7] R. M. Ryan \& E. L.Deci. Self-determination theory and the facilitation of intrinsic, social development, and well-being. American Psychologist, 55, No.1, 68-78, 2000.

[8] E. Ushioda. Motivation, autonomy and sociocultural theory. In Benson (ed.), Learner autonomy 8: Insider perspectives on autonomy in language teaching and learning. Dublin: Authentik, 5-24, 2006.

[9] R. M. Ryan, K. M. Sheldon, T. Kasser \& E. L. Deci. All goals are not created equal: An organismic perspective on the nature of goals and their regulation. In P. M. Gollwitzer \& J. A. Bargh (Eds.), The Psychology of Action: Linking Cognition and Motivation to Behaviour (pp. 7-26). New York: Guilford, 1996.

[10] E. L. Deci \& R. M. Ryan. The "what" and "why" of goal pursuits: Human needs and the self-determination of behavior. Psychological Inquiry, 11, No.4, 227-268, 2000.

[11] R. W. White. Motivation reconsidered: The concept of competence. Psychological Review, 66, 297-333, 1959.

[12] E. A. Skinner. Perceived Control, Motivation, and Coping. Newbury Park, CA: Sage Publications, 1995.

[13] E. L. Deci. Intrinsic motivation. New York: Plenum, 1975.
[14] R. M. Ryan \& J. P. Connell. Perceived locus of causality and internalization: Examining reasons for acting in two dimensions. Journal of Personality and Social Psychology, 57, 749-761, 1989

[15] E. L. Deci, R. Koestner \& R. M. Ryan. A meta-analytic review of examining the effects of extrinsic rewards on intrinsic motivation. Psychological Bulletin, 125, 627-668, 1999.

[16] R. M. Ryan \& C. L. Powelson. Autonomy and relatedness as fundamental to motivation and education, Journal of Experimental Education, 60, No.1, 49-66, 1991

[17] E. L. Deci \& R. M. Ryan. A motivational approach to self: Integration in personality. In R. Dienstbier (Ed.), Nebraska Symposium on Motivation: Vol. 38. Perspectives on Motivation (pp.237-288). Lincoln: University of Nebraska Press, 1991.

[18] R. Baumeister \& M. R. Leary. The need to belong: Desire for interpersonal attachments as a fundamental human motivation. Psychological Bulletin, 117, 497-529, 1995.

[19] R. M. Ryan. Psychological needs and the facilitation of integrative processes. Journal of Personality, 63, 397-427, 1995.

[20] D. Braybrooke. Philosophy of Social Science. Englewood Cliffs, NJ: Prentice-Hall, 1987.

[21] V. F. Filak \& K. M. Sheldon. Student Psychological need satisfaction and college teacher-course evaluations. Educational Psychology, Vol. 23, No.3, 235-247, 2003.

[22] B. Chen, M. Vansteenkiste, W. Beyers, L. Boone, E. L. Deci, B. Duriez,... J. Verstuyf. Basic psychological need satisfaction, need frustration, and need strength across four cultures. Motivation and Emotion, 39, 216-236, 2015.

[23] G. C. Williams \& E. L. Deci. Internalization of biopsychosocial values by medical students: A test of self-determination theory. Journal of Personality and Social Psychology 70, 767-779, 1996.

[24] A. E. Black \& E. L. Deci. The effects of instructors' autonomy support and students' autonomous motivation on learning organic chemistry: A self-determination theory perspective. Science Education, 84, 740-756, 2000.

[25] D. Hooper, J. Coughlan \& M. R. Mullen. Structural equation modelling: Guidelines for determining model fit. The Electronic Journal of Business Research Methods 6, No.1, 53-60, 2008. Retrieved from www.ejbrm.com

[26] R. M. Ryan \& E. L. Deci. Self-regulation and the problem of human autonomy: Does psychology need choice, self-determination, and will? Journal of Personality 74, No. 6, 1557-1585, 2006.

[27] W. F. Hua. On motivations and autonomy of EFL learners. Foreign Languages Research, No,1, 57-62, 2009. (In Chinese)

[28] D. Little. Strategies, counselling and cultural difference: Why we need an anthropological understanding of learner autonomy. In R. Ribé (Ed.), Developing Learner Autonomy in Foreign Language Learning (pp. 17-33). Barcelona: University of Barcelona, 2000.

[29] D. Q. Wang. On cultivating learner autonomy in college 
English education. Foreign Language World, 91, No.5, 17-23, 2002.

[30] M. Mozzon-McPherson \& C. Dantec. Managing language learning at university: An analysis of a strategy-based training programme. In T. Lamb \& H. Reinders (Eds.), Supporting Independent Language Learning: Issues and Interventions (pp. 143-170). Frankfurt: Peter Lang, 2006.

[31] I. Green-Demers \& D. Pelletier. Motivation, goals, and future perspectives of high school students - Outaouais area (Vols. 1 to 14). Gatineau, Canada: Universite' du Que'bec en Outaouais, 2003.

[32] L. Legault, I. Green-Demers \& L. Pelletier. Why do high school students lack motivation in the classroom? Toward an understanding of academic amotivation and the role of social support. Journal of Educational Psychology, 98, 567-582, 2006. Doi: 10.1037/0022-0663.98.3.567.

[33] R. Badri, J. Amani-Saribaglou, G. Ahrari, N. Jahadi, H. Mahmoudi. School Culture, Basic Psychological Needs, Intrinsic Motivation and Academic Achievement: Testing a Casual Model. Mathematics Education Trends and Research, 3, 1-13, 2014. doi:10.5899/2014/metr-00050. Available online at www.ispacs.com/metr

[34] S. Buss. Personal autonomy. The Stanford Encyclopedia of Philosophy (Winter 2014 Edition), Edward N. Zalta (ed.). Online available from http://plato.stanford.edu/archives/win 2014/entries/personal-autonomy/

[35] J. P. Lantolf. Sociocultural Theory and Second Language Learning. Oxford: Oxford University Press, 2000. 